\title{
The Accounting Practices and Environmental Agenda in the Malaysia Airports
}

\author{
Noor Muafiza Masdar, Hanudin Amin and Shariff Umar Shariff Abdul Kadir \\ Labuan Faculty of International Finance, University Malaysia Sabah, 87000 Federal \\ Territory of Labuan, Malaysia
}

\begin{abstract}
The environmental agenda is a big thoughts by the United Nations especially to the aviation business due to its high regulated industry involve. Malaysia is one of the member states and this agenda should be implemented by the airport business. More or less this environmental agenda will influence the accounting practices among Malaysia airports especially in terms of cost and budget allocation. The Malaysia airports have the awareness to implement this environmental practices, however, in which way this practice being implemented and how far it will impact to the accounting approach still being question. Therefore, this study seek to examine the way in which the environmental agenda influences the accounting practices in the Malaysia airports. The data collected in this study are through interviewing the East Malaysia Airports with nine personnel altogether. The observation also take place by visiting the environmental project in the airports. The data then been analyzed by using thematic approach. Underlying to the social capital theory, it is found that Malaysia airports have implemented the environmental practices based on the level of needed and budget that they have. Then, this environmental practices shapes the accounting approaches in terms of budget and cost allocation of the East Malaysia airports.
\end{abstract}

Key words: Accounting Practices, Environmental Agenda, East Malaysia Airports, Social Capital Theory

\section{INTRODUCTION}

Accounting is known as a back bone of the company due to its crucial role in ensuring record keeping of the organization is well tracked. Accounting practices contributed to the management synchronization between upper level management to the lower level management [1]. This situation has shown that accounting in organization is alive crosssectional departments and not limited to the accounting and finance department solely.

Accounting faces revolution over time due to changes in the industrial development and its role in the society [2]. In the aviation industry, the role of regulator is being widely on safety issue and little attention on the environmental issue [3]. However, environmental rising as a serious matter to discuss especially for the future generation [4].

Accounting and environmental issues are closely related in terms of cost and benefits [5] whereby, environmental practices by the organization could reduce the cash outflow of the organization but it is costly at the first installation [6]. This cost and benefit has caught the attention of the Malaysia airports to take charge themselves on the environmental agenda that has been announced by the International Civil Aviation Organization (ICAO).

The Malaysia airports has the awareness on environmental protection by built up the environmental roof and applied the environmental equipment in most of their airports. Environmental education also being exposed to all employees such as green day campaign and the importance of energy saving to humans. The ICAO is an international regulator for airports, thus, Malaysia airports is one of the ICAO state members where they are bound with all regulations including environmental agenda. Due to this obligation, all Malaysia airports have to comply with the rules and regulations. The Malaysia airports execute top down decision making from head office to the branches. Therefore, this study focuses on the airports branches located at the East of Malaysia.

In responding to the environmental issue and the revolution of accounting practices, thus, this study aims to examine the way in which the environmental 
agenda influences the accounting practices in the Malaysia airports.

\section{LITERATURE REVIEWS}

In the business perspective, cost becomes a central and crucial issue to be discussed. It involves a critical financial review by related personnel by focusing on profit maximization of the organization. Nowadays, issue on the environment is a concern to be debatable due to industrial impact to the next future generation. Environment and accounting practices is closely related in terms of cost allocation towards environmental practices in the organization and its benefit to the society and organization [2]. However, some organizations only treat environmental as their procedure in fulfilling the regulations [4] instead of treating environmental practices as a culture need to be practiced by all employees [7].

In China, their organizations are highly concerned about operational cost, environmental impact, and weighted pollutant emission. They claimed environmental impacts and economic development should come together. It means the reduction of waste simultaneously will alleviate the operational cost of the organization [8]. This technical calculation is directly channel to the accounting by looking at the organizational performance and changes in business strategy [9].

The organizational change towards dynamic of environment is a sign of awareness of human life to change including accounting and other related systems [10]. This changes will address to the sustainability of the business [9] and at the same time effect to the accounting practices and record keeping.

Accounting related to environmental perspective leads to the organizational change because it can represent "new voice, new visibilities, and new discourse" for the organization [11]. It means the changes bring organization to the cost effective in their business operations. Other than that, environmental also could create a new image to the eyes of the companies' stakeholders and to attract more shareholders to invest.

In order to look brand new image, companies are willing to change their business operations toward environment and will obligate themselves to the regulator [10]. However, many organizations are naturally reluctant to change and only do so when they are in forced [11]. Organizations have to report their activities to the regulators in ensuring they are really implementing environmental aspects in their business activities.
Regulatory bodies are playing their roles in preparing the standards to be used in this aviation industry. Their roles in supporting the environmental protection divided into two, first, the organization that made a pollution will bear all the damage cost and second, the government will spend money for the prevention [12]. The government will be responsible on the unity environmental protection. Thus, they come out with the environmental certificate to be practiced by the organization in ensuring they are compliance with the rules and regulations. Strong policy by the regulators is needed [13] to ensure the successful of environmental initiative in the airport and organization should be ready to the changes in business practice. This changes involve individual behaviour and responsibility to change the organization as a whole [7]. Every players need to be prepared due to the implementation of environment consume long term period of time such as 20 years from now [14]. If the education and awareness on the importance of environment is already embedded, it could avoid the lobbying issue in getting favorable outcome by the organization [15].

The social capital theory will be used in answering this study on the influences of environmental agenda towards accounting practices. This theory is looking at the connection between airports branches to the head quarter in ensuring the environmental aspects be implemented and at the same time to investigate in which way this environment affect the airports accounting practices. This social capital theory consists of three elements of norms, information, and trust where all of them will become an underlying elements throughout this study.

This theory was formulated by researchers in the field of sociology to discuss about social interaction. Social capital theory is about social structure that discuss on actions of an actor. It tells in which way a person acts towards others and this action can be a single individual or multiple people involved [16]. In addition, this social capital theory was developed to discover the purpose of actions, the selection of relations, and the selection of interactions that lead to opportunities and constraints [17].

This theory consists of three elements which are norms, information, and trust. Norms is a routine and can lead to the powerful force because it reflects to the behaviour a single and group of people in performing activities to achieve the same goal and for collective benefit. Information becomes crucial element in social interactions due to the first aspect been interpreted by people before discussion can be made and it treats as a key element to the top down communication. Next, trust is an obligation that will 
be repaid and this obligations creates long-term relationships in a group of people where the concepts of trust indirectly placed in the people's minds [16]. Trust has a strong connection with information and it will occur voluntarily when good quality information is delivered [18].

In this study, the airport head office transfer the environmental information to the airport branches to be implemented in each department. This information consists of regulation from local and domestic regulators whereby Malaysia airports are bound with environmental certificates in their business operations. The head office also delegate power to the branches in enabling them to make decisions in some level of amount. That is where the head office put their trust on the branches. Aligned with the information given by the head quarter, it becomes a norm of the branches to practice their operation according to the guidelines provided. The branches working practices more considered as a routine by submitting a report to the head office with limited decision making.

\section{METHODOLOGY}

\section{Method}

This study applies a qualitative approach by focusing on the accounting practices and environmental agenda in the Malaysia airports. The case study research being used in obtaining necessary data from various personnel on the accounting practices towards implementation of environmental agenda in the airports. The data collection of this study is using semi-structured interview and observation. The data in this study will be analyzed by using the thematic analysis approach. This approach facilitates an investigation of the interview data from two perspectives: first, a perspective based on coding in an inductive way; second perspective to check if the data were consistent and provide sufficient information [19].

\section{The Selection of Interviewees}

The airports chose in this study is located at the East of Malaysia, where they are bound with environmental regulations by head office also domestic and international regulators. They are been selected due to their crucial involvement in green environment from the east side of Malaysia. In addition, these airports are highly speed growing in terms of number of passengers and aircrafts. Therefore, the environmental pollution widely exists surrounding these airports and in which way these airports synchronized their operations with environmental agenda where ultimately will affect their accounting practices. The technique of semistructured interview was used by interviewing personnel of East Malaysia airports in its branch offices. Other than interviews, researchers also undertook observation in the company and also observation to their clients in the airports.

\section{Data Analysis}

The data collected from the interviews are transcribed manually by using Microsoft Word. The manual data management and analysis being done by focusing on the codes and coding of the data analysis process [20]. These interview transcriptions will be allocated through departments visited. Next, a system of coding will be developed to identify the selected themes. The interview transcripts and observation records will be scrutinized in detail in order to get a picture of the ways in which the environmental agenda influences to the Malaysia airports. Continuous reading of the existing literature and interacting with colleagues enabled researchers to get additional ideas in terms of improving the existing data. Validity of data will be taking place through comprehensive discussion between researchers and employees of the full data collected from the airports, which enabled the interviewees to read and comment on any information on data taken.

\section{FINDING AND DISCUSSIONS}

Accounting practices as an important element in the organization. The accounting process and record keeping will determine how far the company can project their business. The airports in this study has implemented an environmental elements in their operations. However, it is still at a minimum level, especially in the branches. This situation happened due to high cost incurred for installation of environmental equipment in their business.

The Accounting Practices in the Airport Branches The accounting practices in the airports branches most of its are routine work where they need to monitor the cash in and out, do the record keeping, and reported to the head office.

"We record our daily operations and we need to submit our report every month to the head office ... Because head office need to combine all figures" [Executive 1, EA1]. The limitation role of finance department in the airport branch. The annual report prepared by the head office. It can be said, the finance department in the branch involved in routine 
accounting work which is data entry into the system on a daily basis.

"We prepare budget carefully to ensure the event of environmental is success even for small initiative ... Every year we will prepare budget for environmental event" [Executive, EA3]. "We will be audited by many parties like SIRIM, DCA, external auditors, internal auditor from head office ... We have lots of audit ... We need to comply all of them especially to the head office ... We still record the environmental cost that we incurred in branch, but that transaction is not really much significant ... We put under other operating expenses and corporate social responsibility" [Executive 1, EA1]. The responsibility of branch and power delegated to them for some expenditures with limited amount of money. It shows the head office put on trust to the branch for handling on their own.

"Environmental really incurred cost to us ... We are very strict in terms of cash flow" [Executive 1, EA1]. The record keeping and control of accounting record by the branch manager.

\section{The Accounting Practices and Environmental Agenda}

The environmental agenda that announced by the international regulator of aviation is compulsory to practice by the airports especially Malaysia is one of their state members. This practice more or less will influence the accounting practices and cost allocation of the airports.

"Our passengers are increased ... Our revenue also increased in aero spec and airlines ... So, we have our future plans in increasing more on our revenue ... Aero revenue is regulated from international regulator and civil aviation act ... The impact of environmental agenda is not so much significant to us ... We do have green environmental practices but more on the HSE and we have one year planner for this because of the budget ... Sometimes we join the project from airlines such as awareness or else we do the HSE week ... We are more on the safety actually ... We do practice environmental such as cleaning the apron or runaway ... All our campaigns and activities must refer to the head office ... Our revenue in terms of operation wise is growing ... Passenger movement increase ... Our retails lot also almost fully occupied ... So, basically we are growing ... But, we do have financing problem because most of the CAPEX bared by ourselves ... based on our performance and collection ... Our maintenance fees is high and getting higher year by year ... In terms of EBITDA level we are improving but not aggressive, but we are struggle" [Executive 1, EA1]. The accounting record before and after environmental implementation is not much different in the branch because the environmental reporting done by the head office. The branch only in charge for budgeting process and challenge this in the head office and record the cost allocation for the environment.

"In finance, we review the budget prepared by the related department such as HSE ... They cannot simply plug in the figures. We will review thoroughly about the project and price before we submit to the head office for budget challenge ... But the project is already in our plans" [Executive 1, EA1]. "We are still at the early stage in environmental practices ... not all personnel in branch have authority to make a decision and to commit with environmental issue ... Sometimes decision comes in a group direction and most of the time from the head office" [Executive, EA3]. The process of implementing environmental practices by cross-section departments in the branches.

"Our head office now really highlighted about environmental practices ... So, it is a must to include in our yearly project planning ... We shared our cost with other branches and depends on the priority ... The head office will decide all the budget and allocate the shared cost among branches ... All the budgets that we proposed and our plans will be sent to the head office for board meeting and challenge ... Everything done very structured" [Executive 1, EA1]. "We practice environmental operations especially in handling our operating work ... We follow the international environmental handbook for our guidelines ... We follow that guidelines and what boss ask us to do and we practice it in our operations" [Executive, EA2]. The environmental knowledge is shared throughout the airport branches. However, due to cost limitations, the head office put their strategy by prioritize the significant environmental practices with adequate budget based on branch performance. The environmental practices is good but it requires a lot of money to make it sensation.

"Awareness that we practice here is among staff. The information spread out through email ... During lunch break we will switch off all energy in the office, after office hour automatic the airconditioning will be shut down" [Executive 1, EA1]. "We are still learning on the importance of environmental protection and practices ... We are still at the initial stage of awareness ... We communicate through emails, notice board, assembly, WhatsApp group and in many platforms" [Executive, EA3]. "We make our own awareness on the usage of electricity such as lamp. Environmental initiative give a good impact for us and we get used to practice it in our daily working life" [Executive, EA2]. The awareness is embedded among 
employees in airport branches but it is still at the early stage. This practice really takes time to be fully implemented especially in terms of ideology and understanding of environmental protection for the next generation and earth.

"Our big saving on the environmental practice is energy saving ... Such as air-conditioning system, we have chips we call inverter. So, this chips is purposely to reduce the usage of electricity by the air-conditioning" [Executive 2, EA1]. Our main revenue is from airport tax. At the same time our repair and maintenance also high. Thus, we struggle to increase our aero revenue which is tax in enabling us to support the environmental cost ... We are struggling" [Executive 1, EA1]. High cost requires at the initial stage of environmental implementation in the branches including payment to the external party for verification and monitoring the process. However, the airport overseeing this environmental practices in the long run and keep improvise their business from time to time.

"Business nowadays need to apply economic, environment, and social ... In my opinion, every organization is emphasizing these elements in its business. So, finance department need to support this trend ... We can support and guide such as HSE or engineering department on how they want to come out with figure and cost ... It is not a burden to us in finance and to the head office because in whatever situation, we need to comply with regulation and the head office words ... Anyway, it is a good for us" [Executive 1, EA1]. As a highly regulated industry, this business always keep an eye for any new procedures and compulsory to comply with the regulation regardless of the cost it is.

The Environmental Agenda Shapes the Accounting Approaches and Cost Allocation of the East Malaysia Airports

The environmental agenda is implemented in the East Malaysia airports and influenced its accounting approaches in terms of cost reduction and safety enhancement. It is a norm for the airports to follow the procedures given by the head office and this information of procedure has given by the international civil aviation organization. Then, information transfer to the branches will be practiced accordingly and trust also been developed when the head office delegates its power to the branches to approve certain amount of money by themselves. The data found not much different of accounting approach before and after the implementation of environmental agenda in the airport branches because their role is limited to data entry, budget preparation by the engineer or operations, and budget challenge in the head office. All the environmental reporting will be done by the head office but the branches still need to implement the environment in their operating activities. The airport branches still implement the environment elements in its operations even though the initial cost is definitely high. The reason is due to this business is dealing with high regulated industry and always been discussed at the national level for any negligence.

Organizations in Spain not naturally change its operations to environmental operations, but it is only done by force where environmental reporting prevails the practices [11]. The Malaysia airports environmental practices are in line with United Kingdom airport who implement environmental aspects, but requires 10 to 20 years long-term planning in reaching to the environmental point [14]. The environmental agenda is useful and applicable for various industries [21] and harmonized to the shipping industry by looking at their electricity, fuel, and water consumption, also waste decomposition [22]. However, the environmental implementation in multinational firms shown the excessive pollution reduction affects the financial performance and it becomes less interest for firms to continue and comply with environmental practices [23]. The implementation of environment is embedded with skills, awareness, and knowledge of employees. It also integrate with accounting practices and strategic planning processes [24]. Accountant believes the environment is an important issue in business and society, however, the participation of accountants in the environmental practices is still limited [25].

\section{CONCLUSIONS}

Although Malaysia is a member state of the international civil aviation organization, however, the environmental agenda in the airport branches still not fully implemented due to the high cost required. This environment more or less influence to the accounting approaches especially in terms of cost allocation and budget preparation by considering internal and external factors. Thus, the environmental agenda shapes the accounting approaches and cost allocation of the East Malaysia airports. This study is more understandable if the data collection could be expanded to the Finance Department in the head office with the purpose to examine the way in which the environmental agenda affected the accounting process as a whole picture of Malaysia airports. 


\section{Acknowledgements}

The authors would like to thank the University Malaysia Sabah for funding this research grant with project number SBK 0353-2017. The authors also would like to thank colleague for unconditional support and encouragement for this research.

\section{REFERENCES}

[1] Ezzamel, M. \& Robson, K. (1995). Accounting in Time: Organizational Time-Reckoning and Accounting Practice.Critical Perspectives on Accounting, 6, 149-170.

[2] Bartelmus, P. (2015). Do we need ecosystem accounts?. Ecological Economics, 118, 292-298.

[3] Oldham, K., Stanton, J., Bilderbeck, M., \& Spinetto, J. (2017). Case study of a voluntary aviation safety and environmental accreditation programme. Safety Science, 96, 41-51.

[4] Corbett, L. M., \& Cutler, D. J. (2000). Management Environmental management systems in the New Zealand plastics industry. International Journal of Operations \& Production Management, 20(17), 204-224.

[5] Lynes, J. K., \& Andrachuk, M. (2008). Motivations for corporate social and environmental responsibility: A case study of Scandinavian Airlines. Journal of International management, 14(4), 377-390.

[6] Adler, N., \& Gellman, A. (2012). Strategies for managing risk in a changing aviation environment. Journal of air transport management, 21, 24-35.

[7] Lynes, J. K., \& Dredge, D. (2006). Going green: Motivations for environmental commitment in the airline industry. A case study of Scandinavian Airlines. Journal of sustainable tourism, 14(2), 116138.

[8] Lu, B., Du, X., \& Huang, S. (2017). The economic and environmental implications of wastewater management policy in China: From the LCA perspective. Journal of cleaner production, 142, 3544-3557.

[9] Bui, B., \& De Villiers, C. (2017). Business strategies and management accounting in response to climate change risk exposure and regulatory uncertainty. The British Accounting Review, 49(1), 4-24.

[10] Hopwood, A. G. (2009). Accounting and the environment. Accounting, Organizations and Society, 34(3-4), 433-439.

[11] Larrinaga-Gonzalez, C., \& Bebbington, J. (2001). Accounting change or institutional appropriation?-A case study of the implementation of environmental accounting. Critical Perspectives on Accounting, 12(3), 269-292.

[12] Khator, R., Ng, K., \& Chan, H. S. (1992). Environmental management and street???level regulators: A cultural trap? Public Administration and Development, 12(4), 387-397.
[13] Graham, B., \& Guyer, C. (1999). Environmental sustainability, airport capacity and European air transport liberalization: Irreconcilable goals? Journal of Transport Geography, 7(3), 165180.

[14] Upham, P., Thomas, C., Gillingwater, D., \& Raper, D. (2003). Environmental capacity and airport operations: current issues and future prospects. Journal of Air Transport Management, 9(3), 145-151.

[15] Saraswati, S. K. (2001). Operating environment for a civil aviation industry in India. Journal of Air Transport Management, 7, 127-135.

[16] Coleman, J. S. (1988). Social capital in the creation of human capital. American journal of sociology, 94, S95-S120.

[17] Lin, N. (2017). Building a network theory of social capital. In Social capital (pp. 3-28). Routledge.

[18] Fukuyama, F. (2001). Social capital, civil society and development. Third world quarterly, 22(1), 7-20.

[19] Judger, N. (2016). The thematic analysis of interview data: An approach used to examine the influence of the market on curricular provision in Mongolian higher education institutions. Hillary Place Papers ( 3 rd ed.), University of Leeds.

[20] Saldaña, J. (2015). The coding manual for qualitative researchers. Sage.

[21] Mazzi, A., Toniolo, S., Mason, M., Aguiari, F., \& Scipioni, A. (2016). What are the benefits and difficulties in adopting an environmental management system? The opinion of Italian organizations. Journal of cleaner production, 139, 873-885.

[22] Erdas, C., Fokaides, P. A., \& Charalambous, C. (2015). Ecological footprint analysis based awareness creation for energy efficiency and climate change mitigation measures enhancing the environmental management system of Limassol port. Journal of Cleaner Production, 108, 716-724.

[23] Chen, P. H., Ong, C. F., \& Hsu, S. C. (2016). Understanding the relationships between environmental management practices and financial performances of multinational construction firms. Journal of cleaner production, 139, 750-760.

[24] Pérez, E. A., Ruiz, C. C., \& Fenech, F. C. (2007). Environmental management systems as an embedding mechanism: a research note. Accounting, Auditing \& Accountability Journal, 20(3), 403-422.

[25] Wilmshurst, T. D., \& Frost, G. R. (2001). and the Accountant in the Environmental Management System Environment Management, 147, 135-147. 